\title{
IMPACT OF AMENDMENTS MADE TO VALUE ADDED TAX IN 2021 ON PUBLIC AND BUSINESS SECTORS
}

\author{
MAMUKA LEZHAVA \\ PhD Student \\ Ivane Javakhishvili Tbilisi State University, Georgia \\ mamukalezhava1@gmail.com
}

Abstract. Tax administrations play a big role in terms of economic development of the country. Each reform or change implemented by them leave significant imprint on shaping the business environment. Without adopting a fair tax policy, progress in business, as well as in economy is unachievable.

Fulfilment of commitments under the cooperation with EU, represents the state priority. Respectively, the best model of European practice is being established from 2021, further promoting the cooperation between Georgia and EU to move to another level. Considering the abovementioned circumstances, the value-added taxable objects have been substantively changed since 2021 in Georgia. The amendments aim to protect the tax payers' rights, improve the tax regime and approximate it to the European Standard to the maximum extent possible.

As a result of a qualitative research, the expectations both of field experts and business sector representatives towards the amendments made to value added tax since 2021 have been analyzed through an in-depth interview. The research was aimed at defining the further role of the amendments from the perspective of economic development. The impact of implemented reforms on the development of the country's economy was assessed as the research object; and the amendments made to the Tax Code in 2021 and the mechanisms of its functioning were determined as the subject of the research.

KEYWORDS: FINANCIAL GLOBALIZATION, TAX LAW, TAX CODE OF GEORGIA, ECONOMIC MODELING, CHANGES OF VALUE ADDED TAXES, INTERNAL AND EXTERNAL FACTORS.

For citation: Lezhava, M., (2021). Impact of Amendments Made to Value Added Tax in 2021 on Public and Business Sectors. Globalization and Business. 12, 173-176. https://doi.org/10.35945/gb.2021.12.024

\section{INTRODUCTION}

Achieving a high rate of improvement in socio-economic conditions is unimaginable without pursuing proper taxation policy. Therefore, it may safely be said that the taxes are of crucial importance to economic process management. They develop business, nurture and play a special role in the development and production of Gross Domestic Product and in job creation. Unquestionably, the 21st century is the age of challenges and progresses, therefore, for a developing country, like Georgia, the issue of creating the business environment is still relevant today, achievement of which is closely linked with tax policy improvement. Certainly, the issue of perfection is a wide notion. The latter includes tax system throughput, fairness principles and transparency (Bajiv, 2020; Crivelli, 2019; Honaker, 2019). Development of mechanisms for promoting the business environment is a subject of wide discussion nowadays, while, the tax policy undergoes continuous alteration and processing stages, fundamentally changing and shaping the tax issues. On one hand, these processes can be reviewed as an important step forward, and on the other hand, as the means of achieving new opportunities and development. That's why, the recent changes clearly demonstrated that tax burden alleviation is a positive factor for stimulating the economy (Abashidze, 2019; Bukia, 2019). Thanks to tax system reform, many soviet countries managed to improve their social and economic conditions.

\section{RESEARCH DESIGN}

The purpose of the study is to determine what positive and negative effects can have the amendments made to value added tax for such a young economy like Georgia. As a result of qualitative research, mainly, by means of in-depth interview with tax field experts, the forecasts and expectations existing with regards to the changes undertaken in short-or-long term have been reviewed.

The subject of the study are the amendments made to Tax Code of Georgia in 2021 and the mechanisms of its functioning, while the object of the research is the impact 
of implemented reforms on the development of the country's economy. Along with that, for further verification, a hypothesis was developed around the research topic: the amendments made to the Value Added Tax will help raise the tax culture, attract the investments and develop the business sector. It has to be noted, that we have reviewed the example of European countries with the model in force that is approximated to the abovementioned amendments and the results it produced and how it influenced the economic recovery.

\section{RESEARCH ANALYSIS}

Thanks to the tax field amendments made over the recent period, Georgia is approximating to the European tax model. Due to this precise reason, value added taxation modes have been fundamentally changed since 2021. The alterations affected almost all provisions. It has to be remarked that the best model of European practice is gradually being established, which in future, will contribute to and play an important role in close relations between Georgia and European Union and in the development of entrepreneurship.

On one hand, the need to undertake the changes served the purpose of fully protecting taxpayer's interests and on the other hand, approximating the tax system to European Standards as much as possible. Unquestionably, the Value Added Tax is the biggest and most significant tax existing today in Georgia. Accordingly, its fundamental alteration is directly related to the amount of cash inflows in the budget. Obviously, the implemented changes applied both to public and private sectors. The experts of Economic or Tax fields assess these changes as the important step forward, that will facilitate the development of both small and medium businesses. Despite the abovementioned circumstances, the representatives of this field still have various types of remarks or instructions, however, the Ministry of Finance and the Revenue Service operating under it, actively work on this issue. Until this period, there has been issued number of Definitions and Methodology, guiding the tax payer how to minimize confusion and other types of uncertainty. Let's review the important paragraphs that have been fundamentally altered in the Value Added Tax since 2021 and analyze its effect on private or public sectors. Correspondingly, the reader will have the possibility to evaluate, analyze and draw his/her own conclusion how the already implemented reform will contribute to the development or increase of the country's economy (Kbiladze, 2020; Mamrikishvili, 2021).

As mentioned above, the bill elaborated by the Ministry of Finance of Georgia can yield many meaningful results in the short or long term. Naturally, the old bill had its drawbacks, that was eliminated by the changes implemented. As an example, numerous terms have been specified and explained, that were not defined in the Tax Code of Georgia hitherto. Accordingly, the existing circumstance caused the confusion in tax payers. In addition to that, the physical entity, registered as the VAT tax payer, had the obligation to perform financial accounting by accrual method only, and since 2021, the VAT tax payer physical entity has the right to conduct accounting by cash method. Of course, this fact will significantly alleviate the entrepreneur's tax burden and liability to the state, because the cash method of accounting for income and expenses involves direct payment or receipt of cash. And, the accrual method existing before, considers the moment of actual receipt of income and the actual incurrence of expenses regardless of whether the payment has been made. As for the most important change, it applied to the place of service delivery for VAT purposes, which has been defined by two basic principles: on one hand, if a service is provided by a business to a business, the place of establishment of the service purchaser shall be deemed as the Place of Service Delivery. And, on the other hand, if the business renders the services to an individual, the place of establishment of suppliers shall be considered as the Place of Service Delivery. It should be noted that before implementing the aforementioned changes, the type of transaction which was actually performed on the territory of Georgia, was considered as a VAT taxable object. Accordingly, there had been many question marks as what kind of transactions were deemed to be actually performed on the "territory of Georgia", especially in tourism or other sectors. Of course, the new model of service delivery fully provided information to the business and a clear entry has been made in the Tax Code, that will result in raising the culture of the taxpayer. As mentioned above, the new VAT model significantly meets the EU requirements and is in full compliance with European standards. In addition to the changes in the VAT section, Georgia already has the experience in sharing foreign practices, particularly, in terms of amendments made to profit tax. It is noteworthy, that thanks to the changes implemented, poverty and inequality is being reduced in Estonia (Alari, 2018; Cockfield, 2010).

It is a common knowledge that there exists United Nations Human Development Index, according to which, Estonia managed to move from the group of less developed countries to the group of developed nations. Of course, at the moment unemployment and inflation rates in Estonia is low, the living standard has significantly improved (Angelo, 2020; Mathieu, 2020; Sweeney, 2020). The budget is balanced, consistent and, most importantly, complete. Estonia has implemented healthcare and pension reforms to become a full member of the NATO and the European Union. The changes mentioned above, tax policy flawlessness, have enabled Estonia to get prepared to meet the new challenges of the 21st century. Of course, the economy has grown significantly, the market has become free and competitive.

Another example of success is the reform of tax changes in Poland and its positive impact on entrepreneurship. The progress made by the post-Soviet country is internationally recognized. Taxes in the country have changed fundamentally, the pressure on businesses has been reduced, allowing the business entities, operating in the country, to reinvest their own funds and expand their businesses. According to tax experts, a significant amendment was made to gratuitous delivery of goods / services. Compliant to the new reform, free 
delivery of goods will be taxed only if VAT is fully or partially included in this specific expense. Accordingly, this change will significantly help the taxpayer not to shoulder a tax burden. At the same time, the transfer of small value gift / voucher to one physical entity is not considered as gratuitous transfer of goods without compensation. At the same time, the amount should not exceed $50 \mathrm{GEL}$ without VAT during the calendar year. The auditors of leading companies or tax executives are developing the idea that this particular reform will significantly benefit the food business, as the company often delivers food vouchers to loyal customers, and so on. There are quite many facts in Georgian market, when repair works are carried out for own building-facilities and fixed assets used by the company, for the purpose of obtaining economic profit. Compliant to the new reform, the abovementioned transaction will be taxed with VAT only if the entity cannot receive the VAT credit when purchasing goods/services from another entity. When speaking about the benefits for private sector from the amendments made to Value Added Tax, it is necessary to pay attention to the significant allowances that will be received by medical and educational fields as a result of the reforms. In particular, the following types of transactions will be exempted from tax: supply of goods used in the fields of education, culture, sports, medicine and social sciences, unless the right to VAT credit on the mentioned goods has arisen. At the same time, pharmaceuticals/medical goods produced in Georgia are exempted from VAT without the right to VAT credit. Obviously, the tax experts positively evaluate this specific case that will significantly contribute to the emergence of more competitive firms on the market, producing pharmaceuticals or medical goods, and exporting them, if necessary. Most of the companies represented in the Georgian market today are engaged in retail or wholesale trade, including the sale of food, non-food, tobacco products. Nowadays, it is considered to be a natural event, when the deficit is identified during inventory taking/inventory. The deficit revealed for tax code purposes is definitely deemed as the sale and delivery. Correspondingly, the mentioned case is taxed. It is noteworthy, that up to 2021, the loss of goods was taxed according to market prices, at the selling price. As a result of the amendments made, unpaid delivery will be taxed according to the "cost price" instead of market price (Kuparadze, 2016; Papiashvili, 2021). Of course, taxpayer will have significantly less obligation towards the budget and will be able to save funds. It is an internationally recognized practice that the greater the tax burden on the taxpayer is, the more he/she develops an instinct to hide the tax from the budget, therefore, the existing changes enhance the state's care policy.

From 2021, a new term for qualified and non-qualified VAT taxpayer is being introduced. A newly registered company will automatically be granted the status of an unqualified VAT payer, which at this stage, will not be able/authorized to deduct VAT on the performed transactions. After the Revenue Service examines the company's transactions and the taxpayer's good faith, the company will obtain qualified VAT taxpayer status. The current change aims to enable the state to protect itself as much as possible from the taxpayer getting VAT credit through a fictitious transaction. Consequently, the risk of harming the state is drastically reduced. Tax field experts and the experts working on the bill agree that the enacted changes will be most fruitful for legal entities under public law, because as a result of implementation of the reforms, their activities will not fall under economic purposes and therefore will no longer be taxed with value added tax. Of course, this particular change will help public law entities to use their funds for the development, success and innovation of their sector instead of paying them to the budget. At the same time, they will be given a chance to create more state wealth. However, according to experts, there are many open issues regarding legal entities under public law. In particular, what amount of VAT was credited for the expenses incurred on the repair or reconstruction of own buildings/facilities before 2021, whether this amount shall be restored in favor of the budget, alongside with that, whether they have the right to VAT credit. At this stage, the abovementioned issues remain open, but this is temporary and the law is in the process of being refined (Cockfield, 2010; Zylicz, 2019).

\section{CONCLUSION}

Therethrough, the changes made to the Value added Tax after 2021 will, on one hand, help private sector to save, mobilize funds and develop its own business, while, this will raise the taxpayer's awareness, culture and good faith. Creation and establishment of stable business environment will have positive impact on implementation of foreign investments, that will unconditionally increase the country's economy. When making the amendments, the approaches of European Court of Justice to disputed issues have been taken into consideration. Indeed, the amendments made to the Tax Code in 2021 are aimed at achieving tax policy perfection and recognition, introducing the EU standards and establishing the best European practices that will facilitate the international trade and integration and on the other hand, promote the public legal entities to create more state wealth and reinvest their funds. Consequently, the application of European Court rulings and interpretations in practice will, in turn, reduce disputes and make it easier for taxpayers to meet their tax obligations.

\section{REFERENCES:}

Abashidze, K. (2019). Profit Tax and Audit, Tbilisi, 5 (In Georgian).

Alari, P. (2018). Effects of flat tax reforms in Western Europe, FiFo Institute for Public Economics, Warsaw.

Alvarado, M. (2021). European Union - Digital Services Taxes Across Europe in the Midst and Aftermath of the COVID-19 Pandemic: A Plausible Option to Raise Tax Revenue? European Taxation, London. 
Angelo, M. (2020). On the Complementarity between Labour Market Regulation and Tax Reforms in the European Union, Kiev, 12. Antonio, V. (2017). Corporate Tax Reforms and Tax-Motivated Profit Shifting: Evidence from the EU, Audit and Assurance, London. Bajiv, B. (2002). International Tax Competition, Globalisation and Fiscal Sovereignity, published by Commonwealth Secretariat, Warsaw. Barrios, S. (2020). Progressive Tax Reforms in Flat Tax Countries, Brussels, 2.

Barshov, G. (2021). Amendment to the VAT section from 2021, Tbilisi, 3 (In Georgian).

Bukia, I. (2018). Estonian Model of Profit Tax - Economic Growth Prospects. The Economist, Tbilisi (In Georgian).

Bukia, I. (2019). Expectations and Results of Implemented Tax Reforms in Georgia, Tbilisi, 7-8 (In Georgian).

Cockfield, J. (2010). Globalization and its Tax Discontents, Tax Policy and International Investmnets, University of Toronto Press, Paris.

Crivelli, E. (2019). Taxing Multinationals in Europe, Departmental Papers, Warsaw.

Flanagan, R. (2021). EU resurrects plan for single European tax policy, London, 13.

Honaker, K. (2019). Analysis of the Initial Financial Statement Impact of the Tax Cuts and Jobs Act, Paris, 1.

Kanter, J. (2017). Europe Renews Offensive on Silicon Valley With Tax Reforms. Brussels, 2.

Kbiladze, T. (2020). The challenge of defining the optimum tax burden level in Georgia. Tbilisi, 15 (In Georgian).

Kuparadze, G. (2016). The Impact of Tax Policy on Foreign Direct Investment, Tbilisi, 11 (In Georgian).

Mamrikishvili, D. (2021). Changes in Value Added Tax, Tbilisi, 1 (In Georgian) Mathieu, C. (2020). tax reforms in Europe, Warsaw, 3.

Papiashvili, K. (2021). Strategy and Task for VAT Purposes, The Economist, Tbilisi (In Georgian).

Papiashvili, K. (2021). Value Added Tax Reform, The Economist, Tbilisi (In Georgian).

Ries, R. (2019). Tax Cuts and Jobs Act: Impact on Donor Advised Funds, The Cpa Journal, Budapest.

Shenkman, M. (2019). Estate Planning after the Tax Cuts and Jobs Act. London, 5.

Sweeney, P. (2020). Tax wars have so far denied the EU the unanimity required to stop the race to the bottom on corporation tax. Rome, 12.

Syhan B. (2019). IRS Tax Reform Resources, London.

Yiren, K. (2020). The Impact of the Tax Cuts and Jobs Act's Repatriation Tax on Financial Statements, Warsaw.

Zylicz, T. (2019). Europe's experience with carbon-energy taxation. Brussels. 